\section{Prison oral health project wins award}

Dundee dental students have secured an award for an innovative oral health prison project.

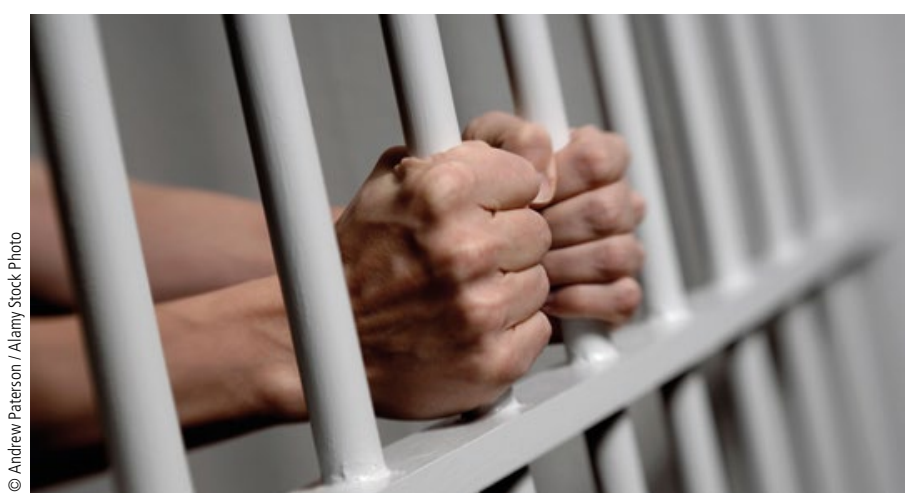

The award was given by Chief Executive of the Oral Health Foundation Dr Nigel Carter while on a recent visit to the University of Dundee School of Dentistry, to judge community oral health projects as part of a judging panel and then present an award to the winning group.

Fourth-year dental students were asked to select an area or group in the local community and then challenged to raise awareness of oral health by showing them how to develop good oral health routines.

As part of their dentistry degree, the students worked alongside voluntary and community organisations which helped them reach out to individuals with mental health issues, the homeless and those with learning disabilities.

The winning group of students was tasked with tackling the issue of oral health for the residents of the Scottish Prison Service (SPS) within HMP Perth.

For the winning group's project, they decided the main areas of focus would be motivation and education, delivered through informational posters and workshops as well as an educational video.

Dr Carter said: 'Every project that was presented to the panel highlighted several fantastic ways we can get important oral health messages and education to those that are more likely to suffer with dental disease.

'The winning team showed excellent knowledge of the problems that prisoners face with their oral health. Their solution was extremely sensible, tackled the key issues and, if rolled-out, could have a positive effect on their wellbeing.

'Studies show that prisoners are more likely to suffer from oral diseases, have lower levels of dental treatment and less motivation to maintain their oral health in comparison to the general population. The oral health of prisoners is often overlooked so measures need to be implemented as to make it a far greater priority'.

The winning group was chosen by a panel of oral health experts, including Dr Carter, who added: 'Every student was enthusiastic and passionate about their project and most importantly, recognised the barriers and challenges of delivering oral health education to more at-risk members of society.

'As a population, it is vital that we continue to work as hard as possible to reduce inequalities and spread positive oral health messages to all members within our communities.'

\section{Child oral health scheme national award announced}

Dental practices are being invited to enter a national competition that recognises success in increasing the number of children aged 0 to 2 years who are accessing dental care.

England's Chief Dental Officer Sara Hurley announced the launch of the 2019 NASDAL Dental Check by One (DCbyl) Practice of the Year award at the recent NASDAL (National Association of Specialist Dental Accountants and Lawyers) biannual conference held at Acton Trussell near Stafford, on 25 April 2019.

The award recognises a practice that has successfully introduced the British Society of Paediatric Dentistry (BSPD) Dental Check by One (DCby1) scheme into their practice.

Established in 2018, the award highlights excellence in the provision of oral care and prevention in children and showcases the opportunity to achieve a real business improvement. Last year's winner was the Maltings Dental Practice in Lincoln.

NASDAL said particular credit would be given to applications from dental practices with evidence supporting their contribution to the overall health of their community.

Sara Hurley said: 'I am delighted to endorse such a worthwhile award. The UK-wide DCbyl campaign was launched by BSPD in partnership with the Office of the Chief Dental Officer England (OCDO) and we are strong supporters of the initiative and early attendance. I look forward to hearing how the entrants have reached out to their communities and engaged with families.'

Liz Roebuck, President of the BSPD welcomed the announcement of the 2019 award, saying: 'When DCby1 was first launched, we were convinced that it would be highly rewarding for the practices that committed to it.

'Our expectations were exceeded with the entries for the 2018 NASDAL DCby1 Practice of the Year Award. We are delighted to continue our support for the award and look forward to reading more inspiring entries in 2019.'

All entries have to be submitted before $5 \mathrm{pm}$ on Friday 30 August 2019.

The winning practice will win $£ 1,000$, a trophy, and the right to use the NASDAL Dental Check by One Practice of the Year 2019 title.

More details and how to enter for the award are available by visiting https://www.nasdal.org.uk/award/index.php.

\section{BDA AGMs}

The Annual General Meeting of the North Western Branch of the BDA will take place on Thursday, 13 June 2019 at the MAX-FAX office, Royal Lancaster Infirmary, Ashton Road, Lancaster LA1 4RP. The meeting begins at 18.30. For details about the event and how to book, visit https://www.bda.org/events/branches-sections/Pages/north-western-branch-thursday-13-june-2019.aspx. 